\title{
Expansion of the current methodology for the study of the short-term liquidity problems in a sector
}

\author{
Elena Rondós-Casas (iD), Salvador Linares-Mustarós (iD, \\ Maria Àngels Farreras-Noguer(D) \\ Universitat de Girona (Spain) \\ elena.rondos@udg.edu,salvador.linares@udg.edu, angels.farreras@udg.edu
}

Received June, 2017

Accepted October, 2017

\section{Abstract}

Purpose: The aim of this work consists of defining and applying a new methodology for the calculation of short-term financial ratios that more reliably approximate the solvency of a sector.

Design/methodology: We begin with a classic sector analysis and propose the creation of ratios that limit the debt repayment on an individual level and that do not imply the compensation of aggregate balances, as occurs with the current formulas of calculation.

Findings: The new methodology more reliably approximates the solvency of a sector by being able to estimate with greater precision its global capacity for short-term debt repayment.

Research limitations/implications: The limitations to the proposed sector ratios are the same as the limitations of the customary individual ratios. Therefore, to offer an example, the ratios do not correct the assumption that the only source of resources to meet current liabilities is made up by available and liquid assets. In other words, no new tools are proposed to include future income from sales by the companies.

Practical implications: To be able to study the solvency of the different sectors that make up the economy with more uniform criteria.

Social implications: The information provided by the new ratios obtained in this work proves to be relevant information in the case of wanting to determine the degree of dependence of companies in a sector on financial institutions, or in the case of wanting to determine the degree of dependence on aid in a subsidized sector.

Originality/value: The proposal of new tools that go beyond the current limitations.

Keywords: Financial ratio, Economic sector, Aggregate data, Financial statements

Jel Codes: B41, C02, C65

\section{Introduction}

The Royal Spanish Academy considers the word "ratio" to be synonymous to the word "proportion" and thus defined as the quotient between two numbers, or in general, two amounts that can be compared to one another. 
Although there are different ways of representing a ratio, currently the most common consists of representing it by means of a fraction written as $\mathrm{A} / \mathrm{B}$.

Mathematically, the numerical value of a ratio can be interpreted as the number of times one of the numbers fits inside the other. In this interpretation, the concept of equivalence between fractions plays an important role, which makes it possible to state that in a ratio with a value $3 / 2(=1.5 / 1)$, the quantity $\mathrm{A}$ is one and a half times quantity $\mathrm{B}$, or that in a ratio with a value $1 / 5(=20 / 100)$, the quantity $\mathrm{A}$ is $20 \%$ of $\mathrm{B}$.

Financial ratios, understood as quotients between two economic magnitudes, owe their enormous expansion in accounting practice to these interpretations. They complement the information provided by the financial statements expressed in monetary units, while at the same time, they can facilitate the comparison over time, with the evolution of the company itself, and in space, as it is possible to make comparisons with other companies in the same industry.

The interest generated by the possibility of analyzing the real situation of a sector through the calculation of financial and economic ratios obtained from the aggregation of the annual accounts of companies that form it (Amat, 2016; Farreras, Linares \& Rondós, 2012; Registradores de España, 2016), has resulted in the emergence of new tangential lines of research, such as the quality of accounting information, the limitations associated with the aggregation of line items and the application of analysis methodologies complementary to the ratios.

The ratios are a tool used by both scholars in their research and professionals in the study of a company or a sector. Bernstein and Wild (1999) state that in traditional financial analysis, ratios represent the final product of the research, as the diagnosis of a specific area of the company is generated based on them. The difference from predictive analysis can be seen here, in that the ratios constitute the raw material that will be processed using statistical techniques and mathematical modeling. These techniques have played a part in generating interest in ratios, leading to an explosion in their use in multiple economic studies. However, it is necessary for the scientific world to know not only about the instruments to be applied, but also accounting science in order to take advantage of their full potential.

There are many different situations in which financial ratios have been used. Among the most important lines, we can mention their use for the analysis of the performance of a company's stock (Soliman, 2008) and its assets (Nissim \& Pemman, 2001; Fairfield \& Yohn, 2001), and to study the evolution of a company in situations of liquidity shortfalls, such as in models predicting bankruptcy (Altman \& Hotchkiss, 2006). Beaver (1966) reached the conclusion that the ratios measuring the cash flows as compared to the indebtedness of the company are the best indicators to predict the financial development of the company.

There are multiple advantages of using ratios, but the most recognized are that they allow for a comparison to be made between companies by eliminating the consequences of the divergence caused by the difference in size (Whittington, 1980; Gallizo, 2005). However, authors like Lev and Sunder (1979) state that the size effect remains unresolved when there is no strict proportionality between the numerator and denominator, and Foster (1986) warns about the importance of controlling for the effect of size differences for the effective application of ratios. There are also several authors who defend the hypothesis that the size of the company is relevant in the financial analysis and this can be undermined if we only use the analysis by ratio methodology (e.g., Serrano Cinca, Mar Molinero \& Gallizo Larraz, 2005; Sudarsanam \& Taffler, 1995).

The latest trends also abandon the introduction of an avalanche of ratios in financial diagnostics, eliminating the so-called pseudo-ratios for not having a causal relationship between the numerator and the denominator, which leads to different types of interpretations of the same coefficient (Lizarraga, 1996; Bukovinsky, 1993). The reality is that it has been more than demonstrated that operating with a few ratios has its benefits.

While it is possible to interpret financial ratios individually, they provide more information when compared to reference values, which can be historical for the same company, standard ratios (Westwick, 1987) or ratios for the sector to which the company belongs. Financial analysts have tried to offer users of their reports some recommended intervals in which they should position the value of each ratio; in this area, we can call attention to 
the contributions made by Lev (1969), who analyzes the different strategies used by companies to reach their optimal values, proposing the hypothesis that there is an equilibrium value for each ratio and in each sector, demonstrating that the ratios undergo a process of adjustment towards the optimal value, which is the response to new strategies by the company or changes in the environment. Gallizo (2005) indicates that we must treat the optimal value as a tool to be used to guide the business management. However, it is necessary to be aware that the users of this methodology can often suffer from a simplistic reduction that can undermine the diagnosis. For example, we might consider the case of interpreting the solvency ratio as part of the short-term debt that can be paid at a certain time with the balances from the investments (also short-term) that become liquid assets throughout the course of the operating cycle. If it is considered that the optimal value of this ratio must belong to the interval of " 1.5 " to " 2 ," which justifies the idea that the short-term asset has a balance of around $50 \%$ or $100 \%$ above the short-term debts so that company presents prompt payment, this consideration could be understood to be excessively simplistic by not including in the study model the different maturities of both assets and liabilities that could indicate the true correlation between the investment and financing, and therefore the real liquidity requirements at each moment. The heterogeneity of the subjects with which we are working makes it difficult to make any sort of generalization that could be applied to every sector, although one of the advantages that has become evident when conducting empirical studies at the sector level is the possibility of using sector ratios as a reference for comparison with those of the analyzed company, which provides an answer as to the position of the individual company in the industry (Suarez, 1999).

The problems that have been detected when working with ratios are different in nature; first of all, we must bear in mind that they are a static magnitude that offers us a view of a company at a specific moment; the analyst must have in-depth knowledge of the peculiarities of the company for which he intends to conduct a diagnosis in order to be able to interpret its balances at the time of drawing the conclusions. One account that can undergo important variations is that of stocks, which can show divergent balances in different years for a same period, according to the purchasing policy of the company for each financial year.

The accounting data, while constituting the basic information we work with, is not by itself free of problems that can alter the image of a company; in this sense, we must refer to the evaluation criteria. There are studies (Shah \& Murtaza, 2000) that indicate the divergence of results when choosing the accounting value or the market value, but we must also refer to the subjectivity that line items can present, such as in the case of amortizations or provisions and the capacity for "window dressing" that can result.

There are also problems related to the very elaboration of the ratios. In this sense, we must present the case in which the denominators are negative or close to zero (Foster, 1986).The best solution when we are faced with this circumstance is to perform an adjustment process, breaking them down into their basic magnitudes and obtaining new financial ratios that offer similar information, but that do not lead to methodological errors.

On a sector level, given that in financial ratios it is common for extreme atypical values to appear as the result of dividing by very small terms (e.g., Ezzamel \& Mar-Molinero, 1990; Frecka \& Hopwood, 1983; Kane, Richardson, \& Meade, 1998), it is not recommendable to use the mathematical mean of the sector ratios as a parameter to represent the set of companies in the industry. This is due to the fact that the extreme values can distort the interpretable results of an aggregate function that is sensitive to them. Oliveras and Moya (2005) warn that if any of the ratios for a sector is very different from the sector mean, the cause must be investigated. In this sense, the present article advises that a single outlier can cause the difference.

Due to problems with asymmetry in the ratio distribution, largely accentuated by the outliers, it is not unusual that the ratio analysis literature has shown a number of works that propose an initial transformation in the data obtained. This includes Box-Cox transformations (e.g., Ezzamel \& Mar-Molinero, 1990; Mcleay \& Omar, 2000; Watson, 1990), logarithmic transformations (e.g., Cowen \& Hoffer, 1982; Deakin, 1976; Sudarsanam \& Taffler, 1995), transformations by ranges (e.g., Kane et al., 1998), by square roots (e.g., Deakin, 1976; Frecka \& Hopwood, 1983; Martikainen, Perttunen, Yli-Olli \& Gunasekaran, 1995), by generalized risk box (e.g., Bahiraie, Azhar \& Ibrahim, 2010), and other processing methods, such as weight of evidence (e.g., Nikolic, ZarkicJoksimovic, Stojanovski \& Joksimovic, 2013), outlier trimming (e.g., Ezzamel \& Mar-Molinero, 1990; Frecka \& 
Hopwood, 1983; Lev \& Sunder, 1979; Martikainen et al., 1995; So, 1987; Watson, 1990), and outlier winsorization (e.g., Lev \& Sunder, 1979).

The present work is focused on improving the financial analysis line of a sector. Specifically, the work presents an alternative to conventional calculations to study the capacity a sector has to make good on its short-term obligations. This option differs from the normal one in the way in which different short-term return ratios are obtained on the sector level. The new sector ratios offer another type of information that is more coherent with a sector's capacity for return.

The work has been organized into three parts. The first section describes the customary methodology used to study the short-term liquidity problems in a sector analysis. An alternative proposal is then presented. In the third part, to show the usefulness of the alternative sector ratio calculation methodology, a sector analysis is conducted on the Catalan agricultural sector. Finally, to conclude the work, a section is presented on the conclusions drawn and the bibliography used.

\section{Current methodology to find the short-term sector financial ratios}

Based on the use of certain financial ratios, this work focuses on the explanation of an alternative calculation used to obtain its value. The starting point for this work is the selection of the ratios to study the short-term solvency of a sector. Without sacrificing generality, three ratios have been chosen whose structure makes it possible to get an idea of the proposed alternative calculation methodology that is being presented. Specifically, the cash flow or acid test ratios, the liquidity or solvency ratios and the current asset ratio + the long-term financial asset, divided by current liabilities. Figure 1 shows its formulation with the customary abbreviations.

\begin{tabular}{|c|c|c|}
\hline \multicolumn{1}{|c|}{$\mathbf{r}_{1}$} & $\mathbf{r}_{2}$ & $\mathbf{r}_{3}$ \\
\hline $\begin{array}{c}\text { cash flow or } \\
\text { acid test ratio }\end{array}$ & $\begin{array}{c}\text { liquidity or solvency } \\
\text { ratio }\end{array}$ & $\begin{array}{c}\text { current asset ratio t the long-term } \\
\text { financial asset, divided by current } \\
\text { liabilities }\end{array}$ \\
\hline$\frac{\mathrm{AC}-\text { Stock }}{\mathrm{PC}}$ & $\frac{\mathrm{AC}}{\mathrm{PC}}$ & $\frac{\mathrm{AC}+\mathrm{IF} / \mathrm{p}}{\mathrm{PC}}$ \\
\hline
\end{tabular}

Figure 1. Definition of three ratios to study the capacity a sector has to make good on its short-term obligations

The customary working methodology to find ratios representative of the sector to be used to establish its state of health consists of calculating the ratios for a specific period, based on the aggregation of numerators and denominators of all the companies in the sector. As a result, given the properties of linearity in the "addition" operation, the sector ratios in Figure 1 can be formulated by the expressions in Figure 2.

\begin{tabular}{|c|c|c|}
\hline $\mathbf{R}_{1}$ & $\mathbf{R}_{\mathbf{2}}$ & $\mathbf{R}_{\mathfrak{s}}$ \\
\hline$\frac{\sum \mathrm{AC}-\sum^{\text {Stocks }}}{\sum \mathrm{PC}}$ & $\frac{\sum \mathrm{AC}}{\sum \mathrm{PC}}$ & $\frac{\sum \mathrm{AC}+\sum_{\mathrm{IF} \_\mathrm{lp}}}{\sum \mathrm{PC}}$ \\
\hline
\end{tabular}

Figure 2. Formulation of the ratios R1, R2 and R3, calculated aggregating data from the sector 
The calculations of the ratios of a sector are represented in capital letters to differentiate them from individual company ratios

For the purpose of clarifying the nomenclature, a detailed model of the calculation of the three ratios is shown with the aid of Table 2, using fictitious data as an example:

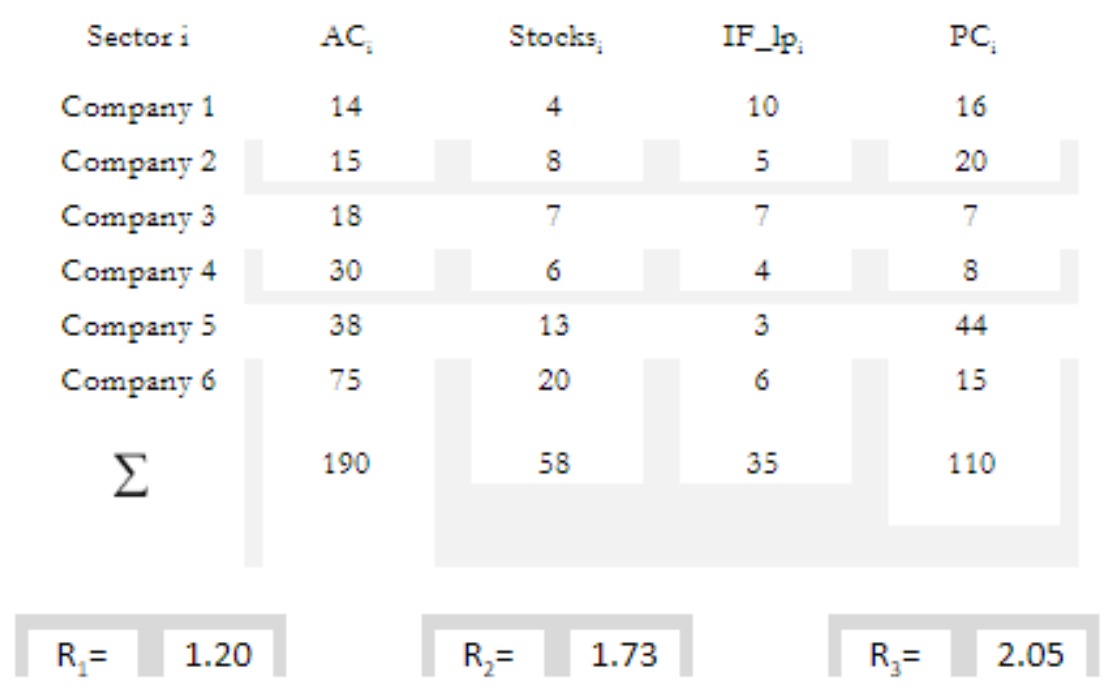

Table 1. Intermediate calculations of the sector liquidity ratio for returns on liquid assets for a specific period

\section{Proposed methodology to find the short-term sector financial ratios}

The calculation of an aggregate ratio poses a fundamental problem that consists of the fact that its use cannot perfectly reflect reality (Linares-Mustarós, Farreras-Noguer, Ferrer-i-Comalat \& Rabaseda-Tarrés, 2013).

Below we see a simplified example to clearly illustrate the previous statement, through the calculation of the acid test ratio.

Let's imagine a sector made up by two companies with the data from Table 2.

\begin{tabular}{|l|r|r|r|}
\cline { 2 - 4 } \multicolumn{1}{c|}{} & \multicolumn{1}{c|}{ AC- Stocks } & PC & \multicolumn{1}{c|}{ Acid test ratio } \\
\hline Company 1 & 15 & 10 & 1.5 \\
\hline Company 2 & 15 & 20 & 0.75 \\
\hline
\end{tabular}

Table 2. Acid test ratio of the sector

In theory, it is evident that the two companies do not have the same capacity to return the entire amount of their liquid debt. Clearly, in a situation with an extremely pessimistic panorama in which the sector could not create any liquid assets from future sales, the table shows that the first company has the capacity to return $100 \%$ of the short-term investment, while the second company only has the capacity to return $75 \%$ of this total investment. If we calculate the aggregate acid test ratio, we would obtain a R1 $=30 / 30=1$, which would lead us to believe that the sector that year has the capacity to return $100 \%$ of the short-term investment, but as we will see, in an extremely pessimistic situation, this statement would be far from the truth. Specifically, given that the first of the companies has a debt of 10 and it can return those 10, and the second company can return only 15 of its debt of 20 , the total percentage of the short-term debt that can be returned under these pessimistic conditions is $(10+15) /(10+20) * 100=83.33 \ldots \%$. 
Therefore, it is necessary to have an indicator that makes it possible to identify what part of the debt in a specific period the companies in a sector will be capable of returning. Studying the evolution of said indicator over time would permit obtaining new information about the variations in the sector's liquidity problems and could help governments and institutions decide which sectors could need certain types of aid. Likewise, said indicator could improve the evaluation of the results of previous aid.

In this sense, Linares et al. (2013) proposed a mathematical formula for a new indicator called the "liquid return sector liquidity ratio," which is defined as follows:

Where $E=\left\{E_{1}, E_{2}, E_{3}, \ldots, E_{n}\right\}$, the set of companies in a specific sector whose acid tests are represented by $\left\{\mathrm{ra}_{1}, \mathrm{ra}_{2}, \mathrm{ra}_{3}, \ldots, \mathrm{ra}_{\mathrm{n}}\right\}$.

The liquid return sector liquidity ratio is defined according to the following expression:

$$
R r a=\frac{\sum \min \left(r a_{i}, 1\right) \cdot P C_{i}}{\sum P C_{i}}
$$

For the purpose of clarifying the nomenclature and seeing how the ratio works, a detailed model of the calculation of the new ratio is shown with the aid of Table 3, using the fictitious data used as an example in Table 2:

\begin{tabular}{|c|c|c|c|c|c|}
\hline Sector i & $A C_{i}-$ stocks $_{i}$ & $\mathrm{PC}_{\mathrm{i}}$ & $\mathrm{ra}_{\mathrm{I}}$ & $\min \left(\mathrm{ra}_{2}, 1\right)$ & $\min \left(\mathrm{ra}_{2}, 1\right) \cdot \mathrm{PC}_{\mathrm{i}}$ \\
\hline Company 1 & 10 & 16 & 0.625 & 0.625 & 10.000 \\
\hline Company 2 & 7 & 20 & 0.350 & 0.350 & 7.000 \\
\hline Company 3 & 11 & 7 & 1.571 & 1.000 & 7.000 \\
\hline Company 4 & 24 & 8 & 3.000 & 1.000 & 8.000 \\
\hline Company 5 & 25 & 44 & 0.568 & 0.568 & 25.000 \\
\hline Company 6 & 55 & 15 & 3.667 & 1.000 & 15.000 \\
\hline $\operatorname{ras}_{\bar{R}}=$ & $\frac{10+}{16+2}$ & $-7+$ & $\frac{-15}{+15}$ & - & \\
\hline
\end{tabular}

Table 3. Calculations of the sector liquidity ratio for returns on liquid assets for a specific period. The ratio indicates that in an excessively pessimistic scenario, the sector only has the capacity to return $65.45 \%$ of the investment made in it

We can see that with the proposed formula, the option for a company to return more than $100 \%$ of what it owes to the sector is eliminated, thus making it possible to obtain a new ratio that can be interpreted as the per unit coefficient of the current liability return capacity in the sector that the group of companies can return in an extremely pessimistic scenario.

Continuing with the present idea of limiting the capacity of a company to return the entire sector debt, the ratios in Figure 1 would be formulated by the expressions in Figure 3. 


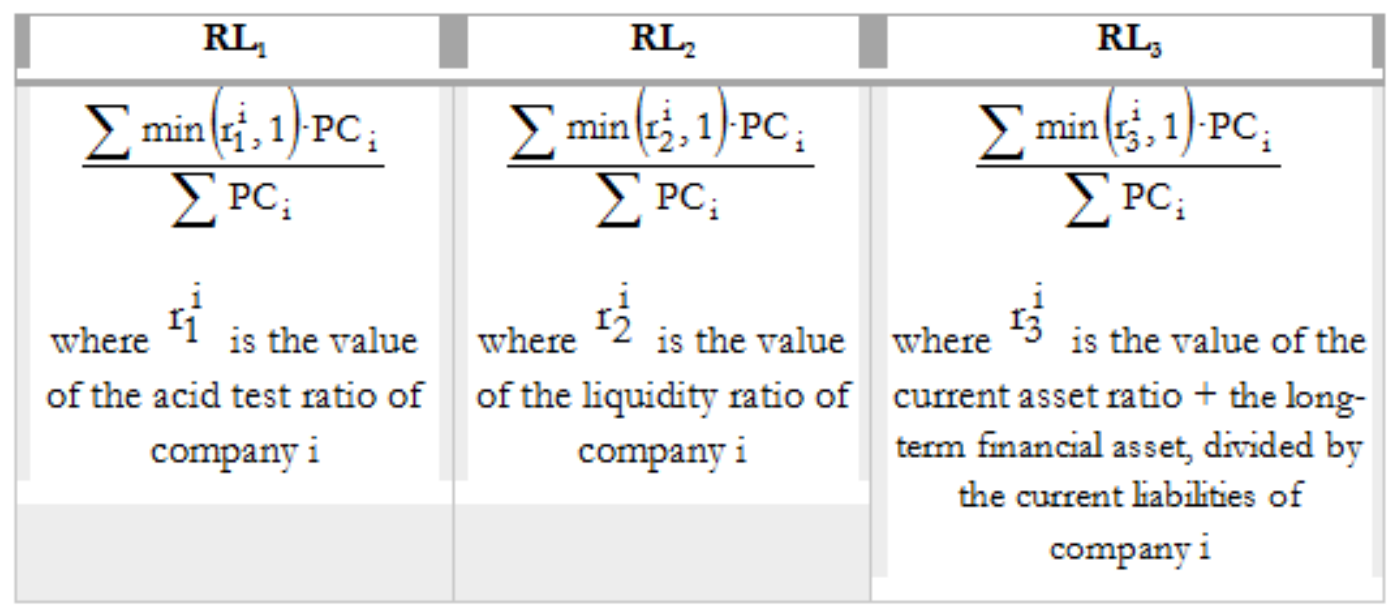

Figure 3. Formula for the ratios $\mathrm{R}_{1}, \mathrm{R}_{2}$ and $\mathrm{R}_{3}$, calculated aggregating data from the sector, with a limitation on the total return of each sector company

\section{Empirical Study}

To analyze the return capacity of the current liability invested in the agricultural sector, the data for the registered companies is analyzed according to the CNAE classification for Group A-Agriculture, livestock keeping, forestry and fishing, and specifically, Subgroup A01-Agriculture, livestock keeping, hunting and related services, located in Catalonia, using the SABI database. The study was conducted between the years 2006 and 2015. The database was consulted on March 10, 2017.

It should be pointed out that the data obtained from this database are from commercial companies from the subgroup that have the legal status of "sociedad limitada" (limited partnership) or "sociedad anónima" (public limited company).

The results are presented below:

\begin{tabular}{|c|c|c|c|c|c|c|c|c|c|c|}
\hline & 2006 & 2007 & 2008 & 2009 & 2010 & 2011 & 2012 & 2013 & 2014 & 2015 \\
\hline No. empl. & 2004 & 1663 & 2059 & 2156 & 2108 & 2290 & 2231 & 2324 & 2352 & 2177 \\
\hline $\mathbf{R}_{1}$ & 0.80 & 0.76 & 0.68 & 0.69 & 0.73 & 0.74 & 0.73 & 0.76 & 0.77 & 0.78 \\
\hline $\mathrm{RL}_{1}$ & 0.55 & 0.52 & 0.50 & 0.49 & 0.51 & 0.50 & 0.49 & 0.52 & 0.52 & 0.51 \\
\hline $\mathbf{R}_{2}$ & 1.27 & 1.28 & 1.18 & 1.22 & 1.30 & 1.31 & 1.33 & 1.30 & 1.28 & 1.31 \\
\hline $\mathbf{R L}_{2}$ & 0.79 & 0.81 & 0.78 & 0.76 & 0.78 & 0.77 & 0.77 & 0.77 & 0.75 & 0.75 \\
\hline $\mathbf{R}_{3}$ & 1.64 & 1.93 & 1.89 & 2.01 & 2.14 & 2.11 & 1.82 & 2.04 & 2.01 & 2.08 \\
\hline $\mathrm{RL}_{3}$ & 0.84 & 0.86 & 0.85 & 0.85 & 0.86 & 0.86 & 0.85 & 0.84 & 0.83 & 0.84 \\
\hline
\end{tabular}

Table 4. Calculations of the three ratios calculated in the traditional manner and as the aggregate sector ratio for the period 2006 to 2015

The first row provides the details of how the number of Catalonian companies has evolved that are dedicated to Subgroup 01 during the analyzed period.

The next two rows $\left(\mathrm{R}_{1}\right.$ and $\left.\mathrm{RL}_{1}\right)$ show the evolution of the cash flow or acid test ratio that relates the most liquid part of the current assets (available + certain) to the current liabilities, thus eliminating the uncertainty associated with stock. If this ratio has a value of between 0.8 and 1 , it is interpreted that the sector will be able to make payments on obligations of less than one year. 
The traditional calculation $\left(\mathrm{R}_{1}\right)$ shows us a subsector that will be able to pay its debts without any problems in most years. The evolution during the years of the study has been fairly constant, with the lowest value in 2008, with 0.68 and the highest in 2006, with 0.80 .

The calculation of the aggregate sector ratio $\left(\mathrm{RL}_{1}\right)$ reveals a subsector with problems in paying its debts. With a constant evolution of around 0.5, the largest figure (0.55) is obtained in 2006, while the smallest occurred in the years 2009 and 2012. These values show a subsector that in an extremely pessimistic scenario could only return half of its debts.

The next two rows $\left(\mathrm{R}_{2}\right.$ and $\left.\mathrm{R}_{2}\right)$ show the evolution of the liquidity ratio, also known as the solvency, current solvency or cash flow ratio, relating the total of current assets to the total of current liabilities. It is estimated that the desirable value would be greater than 1 , and if possible, around 1.5 or as much as 2 .

Such widely varying values owe to the fact that this ratio depends to a great extent on the type of companies we are analyzing and the rotation of accounts receivable and stocks.

Using the traditional calculation $\left(\mathrm{R}_{2}\right)$, the ratios remain above 1.2 for nine years, which indicate a good liquidity situation, especially in 2012, when it exceeds 1.3. The analyzed subsector would have an appropriate payment capacity and its companies would be far from the danger of bankruptcy, at least in the short term.

The calculation of the sector aggregate ratio $\left(\mathrm{RL}_{2}\right)$ shows us a subsector with a compromised liquidity situation, with values between 0.75 and 0.81 for every year studied.

The next two rows $\left(\mathrm{R}_{3}\right.$ and $\left.\mathrm{RL}_{3}\right)$ show the evolution of the ratio that relates the current asset and the financial asset (with group companies and third parties) to the current liability. This ratio takes into account not only the property and short-term rights of the company, it also considers those long-term items that are generally not related to the activity and that could quickly be converted into cash if needed.

The traditional calculation $\left(\mathrm{R}_{3}\right)$ reveals a subsector that has financial investments that could, if necessary, contribute to increasing its liquidity ratio $\left(\mathrm{R}_{2}\right)$ and provide even greater security to its investors. There is an increasing evolution over the years of the study, with the maximum value of 2.14 obtained in 2010 .

If we compare the ratios $R_{2}$ and $R_{3}$, an increase becomes evident, with values between 0.37 and 0.84 .

The calculation of the sector aggregate ratio $\left(\mathrm{RL}_{3}\right)$ shows a constant evolution, with values of nearly 0.85 . If we compare the ratios $\mathrm{RL}_{2}$ and $\mathrm{RL}_{3}$, a growth becomes evident, but with values between 0.05 and 0.09 , what we see is a subsector in which financial investments would obviously help in case of need, but to a very small extent.

A spreadsheet with all the data and calculations can be downloaded at this address:

http://web2.udg.edu/grmfcee/RLs.xls

\section{Conclusions}

This work has shown the usefulness of an alternative methodology for calculating sector ratios. This provides more reliable information on the capacity of a sector to globally return its debt over the short term. It therefore determines with greater precision both is payment capacity and its timeliness.

The ideas are applied in a specific sector in order to find the deviations between the results that have been obtained using the classic ratios and those proposed in this work. The results have shown sufficiently disperse values that corroborate the need to implement these new indicators.

This work has important repercussions on both an academic and social level. On the one hand, the work opens new channels for determining the ideal ratio in a sector. On the other hand, the work warns that current praxis must be refined in the area of sector analysis. 


\section{Declaration of Conflicting Interests}

The authors declared no potential conflicts of interest with respect to the research, authorship, and/or publication of this article.

\section{Funding}

The authors received no financial support for the research, authorship, and/or publication of this article.

\section{References}

Altman, E.I., \& Hotchkiss, E. (2006). Corporate financial distress and bankruptcy: Predict and avoid bankruptcy, analyze and invest in distressed debt (3rd ed.). NJ: Wiley: Hoboken.

Amat, O. (Coordinator)(2016). Manual Ràtios sectorial. ACCID.

Bahiraie, A., Azhar, A.K.M., \& Ibrahim, N.A. (2010). Logistic robust method to new generalized geometric credit risk approach. Applied Mathematical Sciences, 4(2), 51-64.

Bernstein, L.A., \& Wild, J.J. (1999). Financial statement analysis theory. USA: McGrawHill.

Beaver, W.H. (1966). Financial Ratios as Predictors of Failure. Journal of Accounting Research, 4, 71-111. https://doi.org/10.2307/2490171

Bukovinsky, D. (1993). Cash flow and cash position measures in the prediction of business failure: And empirical study. Tesis from Kentucky University.

Cowen, S.S., \& Hoffer, J.A. (1982). Usefulness of financial ratios in a single industry. Journal of Business Research, 10(1), 103-118. https://doi.org/10.1016/0148-2963(82)90020-0

Deakin, E.B. (1976). Distributions of financial accounting ratios: Some empirica levidence. The Accounting Review, 51(1), 90-96.

Ezzamel, M., \& Mar-Molinero, C. (1990). The distributional properties of financial ratios in UK manufacturing companies. Journal of Business Finance \& Accounting, 17(1), 1-29. https://doi.org/10.1111/j.14685957.1990.tb00547.x

Farreras, M.A., Linares, S., \& Rondós, E. (2012) Análisis económico-financiero del sector de la agricultura en Cataluña durante el período 2008-2010. In: IV Congreso Internacional de Agroecoloxía e Agricultura Ecolóxica. Vigo: Universidad de Vigo, 109-137.

Fairfield, P., \& Yohn, T. (2001). Using as set turnover and profit margin to forecast changes in profitability. Review of Accounting Studies, 6, 371-385. https://doi.org/10.1023/A:1012430513430

Foster, G. (1986). Financial Statement Analysis. Englewood Cliffs: Prentice-Hall.

Frecka, T.J., \& Hopwood, W.S. (1983). The effects of outliers on the cross-sectional distributional properties of financial ratios. Accounting Review, 58(1), 115-128.

Gallizo, J.L. (2005). Avances en la investigación de ratios financieros. La dinámica de las ratios. Revista de Contabilidady Dirección, 2, 21-146.

Kane, G.D., Richardson, F.M., \& Meade, N.L. (1998). Rank transformations and the prediction of corporate failure. Contemporary Accounting Research, 15(2), 145-166. https://doi.org/10.1111/j.1911-3846.1998.tb00553.x

Lev, B. (1969). Industry Averages as Targets for Financial Ratios. Journal of Accounting Research, 7, 290-299. https://doi.org/10.2307/2489971

Lev, B. \& Sunder, S. (1979). Methodological issues in the use of financial ratios. Journal of Accounting and Economics, 1(3), 187-210. https://doi.org/10.1016/0165-4101(79)90007-7

Linares-Mustarós, S., Farreras-Noguer, M.A., Ferrer-i-Comalat, J.C., \& Rabaseda-Tarrés, J. (2013). Una nueva ratio sectorial: La ratio de retorno líquido. Cuadernos del CIMBAGE, 15, 57-72. 
Lizarraga Dallo, F. (1996). Modelos multivariantes de previsión del fracaso empresarial: Una aplicación a la realidad de la información contable española. Doctoral thesis, Universidad Pública de Navarra.

Martikainen, T., Perttunen, J., Yli-Olli, P., \& Gunasekaran, A. (1995). Financial ratio distribution irregularities: Implications for ratio classification. European Journal of Operational Research, 80(1), 34-44. https://doi.org/10.1016/0377-2217(93)E0134-J

Mcleay, S., \& Omar, A. (2000). The sensitivity of prediction models to the non-normality of bounded and unbounded financial ratios. The British Accounting Review, 32(2), 213-230. https://doi.org/10.1006/bare.1999.0120

Nikolic, N., Zarkic-Joksimovic, N., Stojanovski, D., \& Joksimovic, I. (2013). The application of brute force logistic regression to corporate credit scoring models: Evidence from Serbian financial statements. Expert Systems with Applications, 40(15), 5932-5944. https://doi.org/10.1016/j.eswa.2013.05.022

Nissim, D., \& Penman, S.H. (2001). Ratio Analysis and Equity Valuation: From Research to Practice. Review of Accounting Studies, 6, 109-154. https://doi.org/10.1023/A:1011338221623

Oliveras, E., \& Moya, S. (2005). La utilización de los datos sectoriales para complementar el análisis de estados financieros. Revista de contabilidad y dirección, 2, 53-69.

Registradores de España (2016). Las Pyme españolas con forma societaria. Colegio de Registradores de la Propiedad, Bienes Muebles y Mercantiles de España.

Serrano Cinca, C., Mar Molinero, C., \& Gallizo Larraz, J.L. (2005). Country and size effects in financial ratios: A European perspective. Global Finance Journal, 16(1), 26-47. https://doi.org/10.1016/j.gfj.2005.05.003

Shah R.J., \& Murtaza M.B. (2000). A Neural network based clustering procedure for bankruptcy prediction. American Business Review, 18, 80-86

Soliman, M.T. (2008). The Use of DuPont Analysis by Market Participants. The Accounting Review, 83(3), 823-853. https://doi.org/10.2308/accr.2008.83.3.823

Suarez, Q. (2004). Las limitaciones del análisis financiero tradicional de la liquidez. Revista Equidad y desarrollo, 2, 101-106.

Sudarsanam, P.S., \& Taffler, R.J. (1995). Financial ratio proportionality and inter-temporal stability: An empirical analysis. Journal of banking \& finance, 19(1), 45-60. https:// doi.org/10.1016/0378-4266(94)00044-4

Watson, C.J. (1990). Multivariate distributional properties, outliers, and transformation of financial ratios. The Accounting Review, 65(3), 682-695.

Westwick, C.A. (1987). Manual para la aplicación de las ratios de gestión. España: Deusto.

So, J.C. (1987). Some empirical evidence on the outliers and the non-normal distribution of financial ratios. Journal of Business Finance \& Accounting, 14(4), 483-496. https://doi.org/10.1111/j.1468-5957.1987.tb00108.x

Whittington, G. (1980). Some Basic Properties of Accounting Ratios. Journal of Business Finance and Accounting, 7(2), 219-223. https://doi.org/10.1111/j.1468-5957.1980.tb00738.x

Intangible Capital, 2018 (www.intangiblecapital.org)

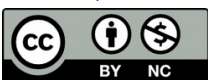

Article's contents are provided on an Attribution-Non Commercial 4.0 Creative commons International License. Readers are allowed to copy, distribute and communicate article's contents, provided the author's and Intangible Capital's names are included. It must not be used for commercial purposes. To see the complete license contents, please visit https://creativecommons.org/licenses/by-nc/4.0/. 